\title{
Evaluating prevalence and risk factors of building-related symptoms among office workers: Seasonal characteristics of symptoms and psychosocial and physical environmental factors
}

\author{
Kenichi Azuma ${ }^{1 *}$, Koichi Ikeda ${ }^{2}$, Naoki Kagi ${ }^{3}$, U Yanagi $^{4}$ and Haruki Osawa ${ }^{5}$
}

\begin{abstract}
Background: Psychosocial and environmental factors at the workplace play a significant role in building-related symptoms (BRSs). Environmental factors change during summer cooling and winter heating using air-conditioning systems. Thus, significant risk factors in each season need to be clarified.

Methods: A nationwide cross-sectional study was conducted during summer in Japan and seasonal differences between summer and winter were evaluated. Self-administered questionnaires were distributed to 489 offices. Possible risk factors for BRSs associated with the work environment, indoor air quality, and job stressors were examined by multiple regression analyses.

Results: Among people having at least one BRS, the prevalence of BRSs in summer (27.8\%) was slightly higher than that in winter (24.9\%). High prevalence was observed for eye and nasal symptoms related to dryness and general symptoms related to psychological distress in both seasons. Analyses revealed that dryness of air was an important and significant risk factor associated with BRSs, and job stressors were significantly associated with general symptoms in both seasons. Conversely, humidity was a significant risk factor of general symptoms in summer (odds ratio, 1.20; 95\% confidence interval, 1.02-1.43). Carpeting, recently painted walls, and unpleasant chemical odors in summer and noise, dust and dirt, and unpleasant odors such as body or food odors in both seasons were significant risk factors for BRSs.
\end{abstract}

Conclusions: Improvements in the physical environmental qualities in an office throughout the year are important along with the reduction in psychological distress related to work.

Keywords: Building-related symptoms, Cross-sectional study, Humidity control, Indoor air quality, Sick Building Syndrome, Occupational stress

\footnotetext{
* Correspondence: kenazuma@med.kindai.ac.jp

${ }^{1}$ Department of Environmental Medicine and Behavioral Science, Kindai University Faculty of Medicine, 377-2 Ohnohigashi, Osakasayama, Osaka 589-8511, Japan

Full list of author information is available at the end of the article
} 


\section{Background}

Nonspecific building-related symptoms (BRSs), commonly called sick building syndrome, have emerged as an environmental and occupational health issue [1]. BRSs relate to situations in which building occupants suffer from respiratory (stuffy and irritated nose, rhinitis, cough, sore throat, and shortness of breath), ocular, skin, and general (fatigue, headache, and fever) symptoms, and these symptoms are relieved when the person is away from the building [2, 3]. Personal factors, including gender $[4,5]$ and personality traits [6]; environmental factors, such as poorly maintained ventilation systems and poor humidification systems [7, 8]; indoor environmental quality; the work environment [4, 9-19]; and occupational stress $[5,14,20-23]$ have been found to be associated with BRSs.

In Japan, the Building Sanitation Management Standards, which specify management standards for the maintenance of indoor air quality, water supply and drainage, cleaning, and pest control were established in 1970. However, the proportion of buildings that do not conform to the standards of relative humidity, room temperature, and carbon dioxide has increased in the last decade in Japan [24]. In addition, development of eye irritation associated with visual display unit work (i.e., computer-related job) in workplaces with low humidity $[25,26]$ and development of upper airway inflammation associated with exposure to particles emitted from photocopiers or laser printers used in the workplace [27] have been suggested.

We firstly conducted a nationwide cross-sectional questionnaire survey on possible risk factors associated with BRSs in office workers working in office buildings during winter in Japan [28]. We also estimated the prevalence of BRSs among office workers in Japan. In the survey, people having at least one BRS accounted for $25 \%$ of the respondents. BRSs were associated with multiple factors, including work environment (carpeting and crowded workspaces), indoor air quality (perception of coldness, perception of air dryness, unpleasant odors, and reported dustiness on the floor), and occupational stress (amount of work and interpersonal conflicts). However, several factors change during summer cooling and winter heating using air-conditioning and heating systems, respectively. In particular, indoor air concentrations of specific volatile organic compounds, including strong irritants of the upper respiratory tract and skin, may increase in summer [29-31]. The relationships between these factors are complicated. Moreover, the proportion of buildings that did not conform to the Building Sanitation Management Standard for relative humidity in their offices has been found to increase in winter [32]. Therefore, significant risk factors in winter (cold season) and summer (hot season) must be clarified.
Following the survey conducted in winter, we conducted a nationwide cross-sectional questionnaire survey in summer to evaluate the prevalence and risk factors of BRSs and evaluated the seasonal characteristics.

\section{Methods \\ Study design and population}

The same study design and the subjects as described in our previous study [28] were used to compare seasonal characteristics. Of 2882 companies belonging to the 47 local prefectural associations of the Japan Building Maintenance Association, 489 companies [four to 50 companies (average 10.4 company) per prefectural association] were recommended by the prefectural association on the basis of the number of companies in a given association. This ensured an even representation across all prefectures in Japan. Each company office was selected from a different building. The two questionnaires, one for the office managers and the other for office workers, working in the office, which was used in our previous study [28] were prepared. The study design was cross-sectional. The participation of office workers was anonymous and voluntary; participants expressed consent to participate through their completion of the questionnaire.

Office workers, such as managers, planning and administrative staff, communication engineers, and designers, who regularly spend long hours in the office during the daytime were selected by the office manager as participants within the office; however, those who were engaged in cleaning the building or measuring indoor air quality were excluded. The overall sizes of the offices in a building included in the study were small because of the small number of office workers who were usually located on one floor alone. These criteria limited the selection of participants. We therefore relied on the office managers to select all office workers when 10 or less office workers in their office met the selection criteria. Otherwise, managers arbitrarily selected 15 office workers at a maximum that met the criteria. Each office manager received a questionnaire to complete, and distributed an additional 15 questionnaires to be completed by their office workers. Surveys were conducted from August to October 2012 (summer) after the previously conducted winter surveys (January to March 2012).

\section{Questionnaires}

As described in detail previously [28], in the questionnaire designed for office managers, the office managers were asked to provide basic information about their offices and the buildings in which they were located, including the total floor area of the building and its year of construction. The questionnaire designed for office workers comprised the United States Environmental 
Protection Agency (USEPA) Questionnaire for indoor environmental quality survey [33], the Indoor Air Questionnaire (MM-40) [34], and the Brief Job Stress Questionnaire $[35,36]$. We added items regarding installed office equipment, mold odor in workplace, and pet ownership at home.

The office workers were asked about their gender, age, job category, smoking status, contact lens use, specific symptoms, frequency of symptoms, association of symptoms with the building, and their perception of the work environment, indoor air quality, and occupational stress. With regard to the work environment, we asked participants the following: the number of people working in the room in which workstation of respondent is located, the condition of their workstation (carpeting, lighting, experience of reflection or glare in the field of vision, table comfort, and chair comfort), computer use, frequency odorous chemical use, any change within five meters of their workstation within the last 3 months (new carpeting, painted walls, furniture, partitions, wall covering, or water damage), the equipment within two meters of the workstation (laser printer, bubble jet printer, copier, exterior window, and door), and indoor workplace installations (fragrance, air freshener, and repellent). In the questionnaire about specific symptoms, we presented a page-long table of symptoms. For each symptom, respondents chose how often the symptom had occurred while working in the building in the last 4 weeks and whether or not the symptom had improved after they left work. In the questionnaire about the perception of indoor air quality, questions were also presented in a page-long table. For each question, respondents chose how often the workplace environmental conditions, such as heat or cold, humidity or dryness, noise, and odors, had been experienced while working in the building during the last 4 weeks.

The job stressor scale comprised 17 general items related to job stress that were rated on a four-point Likert scale ranging from yes (1) to no (4). Responses related to amount of work, mental workload, physical overload, interpersonal conflict, environmental stress, job control, skill utilization, job suitability, and work satisfaction were converted to job stressors using a score translation table. Environmental stress was not included in the following analyses because it is related to other environmental variables such as work environment and perception of indoor air quality.

\section{BRS groups}

As described in detail in our previous study [28], analyses included weekly BRSs, defined as specific symptoms that a person experienced in the building at least 1 day per week in the last 4 weeks and that improved when the person was away from the building. The BRSs include eye irritation, general symptoms, upper respiratory symptoms, lower respiratory symptoms, and skin symptoms. The eye irritation included dry or irritated eyes and tired eyes. The general symptoms included headache, unusual tiredness, tension, difficulty concentrating or remembering things, dizziness, feeling depressed, and nausea. The upper respiratory symptoms included sore or dry throat, sinus congestion, cough, and sneezing. The lower respiratory symptoms included wheezing, chest tightness, and shortness of breath. The skin symptoms included dryness, itching, and irritation of the skin. Thus, 19 symptoms were investigated in total. The symptom group consisted of persons who reported at least one BRS.

\section{Statistical analyses}

While examining the possible risk factors associated with weekly BRSs, the same procedure as in our previous study [28] was used in this study. We examined correlations (Spearman's test) between the variables for multicollinearity by creating a correlation matrix and then scanning for highly correlated variables $(\geq 0.7)$. To prevent multicollinearity, highly correlated variables were not included in the multiple logistic regression model [37, 38]. Univariate associations between BRSs and potential risk factors were examined, and factors with $p<0.2$ were selected for multiple logistic regression analysis.

As described in detail in our previous study [28], personal factors and job stressors were tested using multiple logistic regression analyses to determine potential risk factors associated with BRSs (Model 1). The associations between BRSs and the work environment, adjusting for personal and job stressors, were analyzed (Model 2). The associations between BRSs and the workplace conditions in the last 4 weeks, adjusting for personal factors and job stressors, were analyzed (Model 3). Finally, the selected potential risk factors were included in a stepwise logistic regression analysis (forward selection with Wald statistics) to identify independent risk factors for BRSs (Model 4). The $p$-values for entry and removal of variables in the stepwise logistic regression model were 0.05 and 0.1 , respectively. Goodness of fit was measured with the chi-square test and Hosmer and Lemeshow tests [39].

For examining seasonal differences (between winter and summer) in the prevalence of BRSs, the odds ratio (OR) based on the odds of summer versus those of winter was calculated. Data of our previous study [28] were used for this analysis. Adjusted OR, adjusted for potential confounders of personal factors, which are $p<0.2$ in univariate analyses between winter and summer, was calculated using the Mantel-Haenszel method.

We used $p<0.05$ to indicate statistical significance. ORs and $95 \%$ confidence intervals (CIs) were determined for 
univariate and multivariate associations, and the seasonal comparisons of prevalence. All data analyses were performed using IBM SPSS version 22 for Windows (IBM Corp, Armonk, New York).

\section{Results}

\section{Participants}

Of the original 489 offices, 309 provided office worker responses (response rate, 63.2\%) and 307 provided responses from office managers (response rate, 62.8\%). Two offices provided responses from their office workers but not from the managers. Questionnaire responses were obtained from 3024 office workers, with an average of $9.8(\mathrm{SD}=4.1)$ participant office workers per office.

Characteristics of the participants are shown in Table 1. The mean age was 44.2 years (range, 19-78 years), $38.0 \%$ were women, and most participants had planning or administrative jobs. The mean duration of employment was 7.6 years. The proportions of buildings by year of construction were $9.0 \%, 22.0 \%, 18.0 \%, 36.9 \%$, and $14.1 \%$ in 1950-1969, 1970-1979, 1980-1989, 19901999 , and $\geq 2000$, respectively. Approximately $51 \%$ of the

Table 1 Participant characteristics $(N=3024)$

\begin{tabular}{|c|c|}
\hline Characteristic & Mean \pm SD or $n / N(\%)^{a}$ \\
\hline \multicolumn{2}{|l|}{ Gender } \\
\hline Male & $1859 / 2998(62.0)$ \\
\hline Female & 1139/2998 (38.0) \\
\hline \multicolumn{2}{|l|}{ Age group } \\
\hline $10-19$ & $6 / 2990(0.2)$ \\
\hline $20-29$ & $352 / 2990(11.8)$ \\
\hline $30-39$ & $807 / 2990(27.0)$ \\
\hline $40-49$ & $794 / 2990(26.6)$ \\
\hline $50-59$ & $645 / 2990(21.6)$ \\
\hline$\geq 60$ & $386 / 2990(12.9)$ \\
\hline \multicolumn{2}{|l|}{ Job categories } \\
\hline Managerial & $656 / 2947(22.3)$ \\
\hline Professional & $139 / 2947(4.7)$ \\
\hline Technical & $415 / 2947(14.1)$ \\
\hline Sales & $363 / 2947(12.3)$ \\
\hline Planning/administrative & $1223 / 2947(41.5)$ \\
\hline Secretarial/clerical & $6 / 2947(0.2)$ \\
\hline Other & $145 / 2947(4.9)$ \\
\hline \multicolumn{2}{|l|}{ Smoking status } \\
\hline Never & $1286 / 3006(42.8)$ \\
\hline Former & $714 / 3006(23.8)$ \\
\hline Current/sometime & $99 / 3006(3.3)$ \\
\hline Current/everyday & $907 / 3006(30.2)$ \\
\hline Mean year working in the building $(n=2997)$ & $7.6 \pm 7.1$ \\
\hline
\end{tabular}

${ }^{a}$ Data for characteristics were missing for some participants (no response) buildings surveyed in this study were built after 1990 . The proportions of building in terms of its total floor area were $47.3 \%, 20.5 \%, 6.7 \%, 11.7 \%, 9.4 \%$, and $4.4 \%$ for $<1000 \mathrm{~m}^{2}, 1000$ to $<3000 \mathrm{~m}^{2}, 3000$ to $<5000 \mathrm{~m}^{2}, 5000$ to $<10,000 \mathrm{~m}^{2}, 10,000$ to $<50,000 \mathrm{~m}^{2}$, and $\geq 50,000 \mathrm{~m}^{2}$, respectively.

\section{Prevalence of BRSs}

The prevalence of 19 health symptoms related to work environments are shown in Table 2. Weekly BRS is defined as symptoms experienced at least 1 day per week in the last 4 weeks that improved when one was away from the building. Monthly BRS shows symptoms that are experienced at least 1 day in the last 4 weeks that improved when one was away from the building.

The prevalence of weekly BRSs in terms of eye irritation, general symptoms, upper respiratory symptoms, lower respiratory symptoms, and skin symptoms was $14.1 \%, 18.3 \%, 6.7 \%, 0.9 \%$, and $2.2 \%$, respectively. The prevalence of those symptoms (weekly), irrespective of whether the symptoms improved when away from work, was $29.3 \%, 31.8 \%, 22.2 \%, 3.6 \%$, and $8.0 \%$, respectively. Thus, the proportions of symptoms related to the work environment were $48.1 \%, 57.5 \%, 30.0 \%, 24.8 \%$, and $27.0 \%$, respectively. In the BRSs, the prevalence of lower respiratory symptoms was very low; so, this symptom group was excluded from subsequent modeling.

\section{Risk factors associated with BRSs}

We examined the correlations among 53 variables (7 personal factors, 22 work environment factors, 16 indoor air quality factors, and 8 job stressors). No highly correlated variables (correlation $\geq 0.7$ ) existed. Univariate associations between BRSs and all personal and other variables, and the numbers of cases by variable factors for weekly BRSs are presented in the Additional file 1 (Table S1 and Table S2, respectively). The subsequent results of multiple logistic regression analysis models for the association with weekly BRSs are shown in Table 3 (Model 1), Table 4 (Model 2), Table 5 (Model 3), and Table 6 (Model 4), and the results of the risk factors associated with weekly BRSs are described below.

\section{Personal factors}

All BRSs were significantly increased in females (Tables 3 and 6). A younger age (20-29 years, followed by $30-39$ years) significantly increased the possibility of reported general symptoms. Current smoking was not related to BRSs (Table 3). Contact lens use was significantly related to eye irritation and upper respiratory symptoms. Owning a cat as a pet was significantly associated with skin symptoms (Table 6). 
Table 2 Prevalence of health symptoms related to work environments $(N=3024)$

\begin{tabular}{|c|c|c|}
\hline Symptoms & Weekly $^{a} \mathrm{n} / \mathrm{N}(\%)^{b}$ & Monthly ${ }^{c} \mathrm{n} / \mathrm{N}(\%)^{b}$ \\
\hline Tension, irritability, or nervousness & $327 / 2825(11.6)$ & $245 / 2825(8.7)$ \\
\hline Tired or strained eyes & $286 / 2800(10.2)$ & $171 / 2800(6.1)$ \\
\hline Dry, itching, or irritated eyes & $222 / 2952(7.5)$ & $121 / 2952(4.1)$ \\
\hline Feeling depressed & 195/2857 (6.8) & $179 / 2857(6.3)$ \\
\hline Unusual tiredness, fatigue, or drowsiness & 186/2911 (6.4) & $143 / 2911(4.9)$ \\
\hline Sore or dry throat & $108 / 2919(3.7)$ & $108 / 2919(3.7)$ \\
\hline Headache & $78 / 2938(2.7)$ & $168 / 2938(5.7)$ \\
\hline Difficulty remembering things or concentration & $62 / 2837(2.2)$ & 104/2837 (3.7) \\
\hline Sneezing & $52 / 2828(1.8)$ & 102/2828 (3.6) \\
\hline Cough & $36 / 2902(1.2)$ & $84 / 2902(2.9)$ \\
\hline Dry or flushed facial skin & $36 / 2974(1.2)$ & $37 / 2974(1.2)$ \\
\hline Stuffy or runny nose, or sinus congestion & $34 / 2893(1.2)$ & $63 / 2893(2.2)$ \\
\hline Hands dry, Itching, red skin & $33 / 2963(1.1)$ & 26/2963 (0.9) \\
\hline Dizziness or lightheadedness & $32 / 2928(1.1)$ & $65 / 2928(2.2)$ \\
\hline Nausea or upset stomach & $32 / 2941(1.1)$ & $65 / 2941(2.2)$ \\
\hline Scaling/itching scalp or ears & 23/2961 (0.8) & 26/2961 (0.9) \\
\hline Shortness of breath & $15 / 2978(0.5)$ & $32 / 2978(1.1)$ \\
\hline Chest tightness & 15/2995 (0.5) & 49/2995 (1.6) \\
\hline Wheezing & $7 / 3003(0.2)$ & 17/3003 (0.6) \\
\hline Total $^{d}$ & $721 / 2597(27.8)$ & $1330 / 2666(42.4)$ \\
\hline
\end{tabular}

\section{Job stressors}

As shown in Table 3, multivariate analyses revealed that many stressors, such as excessive work, high mental workload, strong interpersonal conflict, low job control, and low work satisfaction, were significantly associated with general symptoms (Model 1). Even after being adjusted for additional variables of work environment and workplace conditions in the final multivariate model (Model 4), these associations persisted, apart from the association with high mental workload (Table 6). Excessive work, high mental workload, low physical overload, strong interpersonal conflict, and low skill utilization were significantly associated with eye irritation, and excessive work and strong interpersonal conflict significantly increased the reporting of upper respiratory symptoms (Table 3, Model 1 ). The association with strong interpersonal conflict was also significant in skin symptoms. However, the associations did not persist after adjusting for other variables in the final model (Model 4) apart from the association with excessive work and low physical overload (Table 6).

\section{Work environment}

No significant association between the office equipment and BRSs was observed (Table 4, Model 2). In the final model (Table 6), a crowded workplace was significantly associated with eye irritation. Carpeting and uncomfortable seating were significantly associated with eye irritation, general symptoms, and upper respiratory symptoms. Often a reflection or glare was significantly associated with eye irritation and general symptoms. The increased use of odorous chemicals was significantly associated with eye irritation. The association between eye irritation and working on the computer was strongly significant (OR, 5.51; 95\% CI, 1.62-18.73) (Model 4). The association between upper respiratory symptoms and recently painted wall (in the last 3 months) in the workplace within five meters of a workstation was also strongly significant (OR, 4.72; 95\% CI, 1.57-14.22) (Model 4).

\section{Workplace conditions}

In the associations between the workplace conditions in the last 4 weeks and BRSs, multivariate analyses revealed that all symptoms were significantly associated with airconditioning factors and unpleasant odors (e.g., body, food, or chemical odors) (Tables 5 and 6). In the final model (Model 4), dryness of air was significantly associated with eye irritation, upper respiratory symptoms, 
Table 3 The association of weekly building-related symptoms with personal factors and job stressors (Model 1)

\begin{tabular}{|c|c|c|c|c|}
\hline \multirow[t]{2}{*}{ Variable factors } & $\begin{array}{l}\text { Eye irritation } \\
\text { OR }(95 \% \mathrm{Cl})\end{array}$ & $\begin{array}{l}\text { General symptoms } \\
\text { OR }(95 \% \mathrm{Cl})\end{array}$ & $\begin{array}{l}\text { Upper respiratory } \\
\text { OR ( } 95 \% \mathrm{Cl})\end{array}$ & $\begin{array}{l}\text { Skin symptoms } \\
\text { OR }(95 \% \mathrm{Cl})\end{array}$ \\
\hline & $N=2590$ & $N=2505$ & $N=2486$ & $N=2687$ \\
\hline \multicolumn{5}{|l|}{ Personal } \\
\hline Gender (female) & $2.17(1.53-3.09)^{* *}$ & $2.19(1.57-3.05)^{* *}$ & $2.33(1.42-3.83)^{* *}$ & $5.05(2.10-12.14)^{* *}$ \\
\hline \multicolumn{5}{|l|}{ Age } \\
\hline $10-19$ & $1.45(0.15-14.02)$ & $1.14(0.12-10.68)$ & $2.98(0.29-30.11)$ & - \\
\hline $20-29$ & $2.06(1.15-3.67)^{*}$ & $2.34(1.37-3.99)^{* *}$ & $1.69(0.77-3.69)$ & $0.74(0.25-2.16)$ \\
\hline 30-39 & $1.65(0.96-2.84)$ & $1.74(1.07-2.85)^{*}$ & $1.40(0.67-2.92)$ & $0.68(0.27-1.75)$ \\
\hline $40-49$ & $1.26(0.73-2.17)$ & $1.12(0.68-1.84)$ & $0.87(0.41-1.86)$ & $0.46(0.17-1.24)$ \\
\hline $50-59$ & $1.76(1.02-3.03)^{*}$ & $1.18(0.71-1.96)$ & $1.13(0.53-2.42)$ & $0.37(0.13-1.06)$ \\
\hline$\geq 60$ & Ref. & Ref. & Ref. & Ref. \\
\hline$p$ for trend & 0.048 & $<0.001$ & 0.149 & 0.425 \\
\hline \multicolumn{5}{|l|}{ Job categories } \\
\hline Managerial & Ref. & Ref. & Ref. & Ref. \\
\hline Professional & $0.61(0.27-1.36)$ & $0.77(0.39-1.52)$ & $0.83(0.23-3.04)$ & $0.60(0.07-5.37)$ \\
\hline Technical & $0.49(0.28-0.86)^{*}$ & $0.76(0.48-1.19)$ & $1.35(0.61-2.97)$ & $0.56(0.11-2.96)$ \\
\hline Sales & $0.67(0.41-1.10)$ & $0.90(0.58-1.39)$ & $1.06(0.46-2.46)$ & $1.06(0.25-4.54)$ \\
\hline Planning/administrative & $1.17(0.78-1.75)$ & $1.25(0.84-1.85)$ & $2.39(1.20-4.76)^{*}$ & $1.72(0.56-5.29)$ \\
\hline Secretarial/clerical & $2.16(0.33-14.34)$ & $0.78(0.08-7.65)$ & $8.85(1.29-60.90)^{*}$ & - \\
\hline Other & $0.50(0.20-1.24)$ & $1.02(0.51-2.03)$ & $1.96(0.70-5.46)$ & $2.19(0.55-8.64)$ \\
\hline \multicolumn{5}{|l|}{ Smoking } \\
\hline Never & Ref. & Ref. & Ref. & Ref. \\
\hline Former & $0.91(0.65-1.27)$ & $0.99(0.72-1.35)$ & $1.22(0.77-1.93)$ & $1.77(0.87-3.63)$ \\
\hline Current/sometime & $0.99(0.48-2.06)$ & $0.75(0.35-1.58)$ & $1.08(0.40-2.95)$ & $1.09(0.14-8.43)$ \\
\hline Current/everyday & $0.93(0.68-1.27)$ & $0.89(0.66-1.20)$ & $0.95(0.60-1.50)$ & $1.54(0.74-3.18)$ \\
\hline Contact lens use & $1.49(1.14-1.95)^{* *}$ & $1.20(0.92-1.57)$ & $1.46(1.00-2.12)^{*}$ & $1.18(0.63-2.19)^{*}$ \\
\hline Pet ownership (Cat) & & & $1.79(1.07-2.99)^{*}$ & $3.16(1.59-6.28)^{* *}$ \\
\hline \multicolumn{5}{|l|}{ Job stressors } \\
\hline Amount of work ${ }^{a}$ & $1.24(1.08-1.42)^{* *}$ & $1.27(1.11-1.44)^{* *}$ & $1.28(1.09-1.49)^{* *}$ & \\
\hline Mental workload ${ }^{a}$ & $1.19(1.01-1.39)^{*}$ & $1.19(1.03-1.39)^{*}$ & & \\
\hline Physical overload ${ }^{b}$ & $0.77(0.65-0.91)^{* *}$ & $0.93(0.79-1.08)$ & $1.06(0.84-1.33)$ & \\
\hline Interpersonal conflict ${ }^{a}$ & $1.16(1.01-1.33)^{*}$ & $1.69(1.47-1.94)^{* *}$ & $1.25(1.04-1.51)^{*}$ & $1.72(1.27-2.32)^{* *}$ \\
\hline Job control ${ }^{a}$ & $0.91(0.80-1.04)$ & $0.77(0.68-0.87)^{* *}$ & $0.94(0.78-1.12)$ & $0.91(0.68-1.21)$ \\
\hline Skill utilization ${ }^{c}$ & $0.84(0.71-0.98)^{*}$ & $0.95(0.81-1.11)$ & $0.87(0.70-1.07)$ & $1.06(0.74-1.51)$ \\
\hline Job suitability ${ }^{d}$ & $0.96(0.82-1.12)$ & $1.12(0.96-1.30)$ & $1.02(0.82-1.26)$ & \\
\hline Work satisfaction ${ }^{d}$ & $0.97(0.83-1.14)$ & $0.68(0.58-0.79)^{* *}$ & $0.84(0.67-1.05)$ & $1.02(0.77-1.36)$ \\
\hline
\end{tabular}

Values are expressed as adjusted odds ratios $(95 \% \mathrm{Cl})$ for participants with complete data. Variables with $p<0.2$ in univariate analyses are included in a multivariate logistic regression analysis. Ref. $=$ referent. Significant at ${ }^{*} p<0.05,{ }^{* *} p<0.01$. Text in parentheses reflects case groups

${ }^{a}$ Five levels of response are 1) less/low, 2) somewhat less/low, 3) medium, 4) somewhat more/high, and 5) more/high

${ }^{b}$ Four levels of response are 1) somewhat less/low, 2) medium, 3) somewhat more/high, and 4) more/high

${ }^{c}$ Four levels of response are 1) less/low, 2) somewhat less/low, 3) medium, and 4) somewhat more/high

${ }^{d}$ Four levels of response are 1) less/low, 2) somewhat less/low, 3) medium, and 4) more/high

and skin symptoms (Table 6). Mucosal dryness involves these symptoms. The association with skin symptoms was strongest (OR, 2.71; 95\% CI, 2.10-3.51). However, general symptoms were significantly associated with humidity and cold. The association between unpleasant chemical odors (e.g., cleanser, glue, correction fluid, or other odorous chemicals) and skin symptoms was the strongest in indoor pollutant factors (OR, 2.60; 95\% CI, 1.63-4.15). Noise was significantly associated with eye irritation, general symptoms, and upper respiratory symptoms. 
Table 4 Associations between weekly building-related symptoms and the work environment (Model 2)

\begin{tabular}{|c|c|c|c|c|}
\hline \multirow[t]{2}{*}{ Variable factors } & \multirow{2}{*}{$\begin{array}{l}\text { Eye irritation } \\
\text { OR }(95 \% \mathrm{Cl}) \\
N=2332\end{array}$} & \multirow{2}{*}{$\begin{array}{l}\text { General symptoms } \\
\text { OR }(95 \% \mathrm{Cl}) \\
N=2275\end{array}$} & \multirow{2}{*}{$\begin{array}{l}\text { Upper respiratory } \\
\text { OR }(95 \% \mathrm{Cl}) \\
N=2262\end{array}$} & \multirow{2}{*}{$\begin{array}{l}\text { Skin symptoms } \\
\text { OR }(95 \% \mathrm{Cl}) \\
N=2438\end{array}$} \\
\hline & & & & \\
\hline No. of people in office ${ }^{a}$ & $1.16(1.00-1.36)$ & $1.13(0.97-1.31)$ & $1.11(0.89-1.38)$ & $1.15(0.81-1.64)$ \\
\hline \multicolumn{5}{|l|}{ Work station } \\
\hline Floor carpet (with) & $1.53(1.13-2.06)^{* *}$ & $1.56(1.17-2.08)^{* *}$ & $1.77(1.13-2.78)^{*}$ & $3.07(1.30-7.27))^{*}$ \\
\hline Lighting $^{b}$ & $0.77(0.58-1.01)$ & $0.89(0.68-1.17)$ & $0.64(0.45-0.93)^{*}$ & $0.62(0.35-1.09)$ \\
\hline Reflection or glare in vision ${ }^{c}$ & $1.42(1.23-1.66)^{* *}$ & $1.48(1.27-1.72)^{* *}$ & $1.49(1.22-1.82)^{* *}$ & $1.61(1.21-2.16)^{* *}$ \\
\hline Table comfort ${ }^{d}$ & $1.03(0.82-1.31)$ & $1.07(0.85-1.35)$ & $0.88(0.63-1.22)$ & $1.31(0.78-2.18)$ \\
\hline Chair comfort $^{d}$ & $1.48(1.19-1.86)^{* *}$ & $1.58(1.27-1.96)^{* *}$ & $2.06(1.53-2.79)^{* *}$ & $1.18(0.72-1.95)$ \\
\hline Work with computer & $3.53(1.03-12.18){ }^{*}$ & $1.41(0.66-3.03)$ & & \\
\hline Use of odorous chemicals ${ }^{e}$ & $1.14(1.05-1.23)^{* *}$ & $1.10(1.02-1.19)^{*}$ & $1.06(0.94-1.19)$ & $0.98(0.81-1.19)$ \\
\hline \multicolumn{5}{|l|}{ Change in workplace ${ }^{f}$} \\
\hline New carpeting & $0.99(0.36-2.75)$ & & $0.52(0.11-2.40)$ & \\
\hline Painted wall & & & $5.96(1.16-30.64)^{*}$ & \\
\hline New furniture & $0.88(0.48-1.63)$ & & $1.06(0.44-2.56)$ & \\
\hline New wall covering & $1.19(0.43-3.28)$ & & $1.19(0.22-6.47)$ & \\
\hline Water damage & & & & $1.32(0.40-4.35)$ \\
\hline \multicolumn{5}{|l|}{ Equipment/installation } \\
\hline Laser printer $^{g}$ & $1.11(0.83-1.50)$ & $0.96(0.72-1.29)$ & & \\
\hline Bubble jet printer ${ }^{g}$ & $1.05(0.79-1.40)$ & $1.02(0.77-1.36)$ & & $1.71(0.92-3.18)$ \\
\hline Copier $^{g}$ & $1.25(0.92-1.70)$ & $1.33(0.99-1.78)$ & $1.20(0.81-1.77)$ & $1.64(0.88-3.07)$ \\
\hline Exterior window ${ }^{g}$ & & & $0.79(0.54-1.16)$ & \\
\hline Door $^{9}$ & $0.71(0.52-0.97)$ & & & \\
\hline Fragrance $^{h}$ & & & & $1.59(0.59-4.26)$ \\
\hline Air freshener ${ }^{h}$ & & $1.04(0.71-1.44)$ & $1.15(0.67-1.98)$ & \\
\hline Repellent $^{h}$ & & & $1.15(0.66-2.03)$ & $0.63(0.23-1.72)$ \\
\hline \multicolumn{5}{|c|}{$\begin{array}{l}\text { Values are expressed as adjusted odds ratios }(95 \% \mathrm{Cl}) \text { for participants with complete data. Values are adjusted for personal factors and job stressors with } p< \\
\text { univariate analyses using multivariate regression analysis. Ref. = referent. Significant at }{ }^{*} p<0.05,{ }^{* *} p<0.01 \text {. Text in parentheses reflects case groups } \\
{ }^{a} \text { Number of people working in the room in which workstation of respondent is located. Six levels of response are 1) } 1 \text { person, 2) } 2-3 \text { persons, 3) 4-7 person } \\
8-20 \text { persons, 5) 21-50 persons, and 6) } \geq 51 \text { persons } \\
{ }^{b} \text { Five levels of response are 1) much too dim, 2) a little too dim, 3) Just right, 4) a little too bright, and 5) much too bright } \\
{ }^{c} \text { Five levels of response are 1) rarely, 2) occasionally, 3) sometimes, 4) fairly often, and 5) very often } \\
{ }^{d} \text { Four levels of response are 1) very comfortable, 2) reasonably comfortable, 3) somewhat uncomfortable, and 4) very uncomfortable } \\
{ }^{e} \text { Five levels of response are 1) never, 2) less than } 3 \text { times/week, 3) 3-4 times a week, 4) about once a week, and 5) several times a day; with cleanser, glue, } \\
\text { correction fluid, or other odorous chemicals } \\
{ }^{f} \text { Change taken place within five meters of workstation in last } 3 \text { months } \\
{ }^{g} \text { Within two meters of workstation } \\
{ }^{h} \text { In workplace indoors }\end{array}$} \\
\hline
\end{tabular}

\section{Seasonal comparisons of prevalence and risk factors of BRSs}

In winter, of the original 489 offices, 320 offices provided office worker responses, and questionnaire responses were obtained from 3335 office workers [28]. In summer, 3024 questionnaire responses from 309 offices that were provided from its office workers were obtained. The number of offices providing questionnaire responses from office workers in both winter and summer was 246.

The comparison of the prevalence of weekly BRSs between winter and summer is shown in Table 7 .
Univariate analyses (based on a chi-square test) comparing personal factors between winter and summer indicated statistically differences $(p<0.2)$ across age, gender, and job. Adjusted OR was calculated by the Mantel-Haenszel method and adjusted for these personal factors. The prevalence of three general symptoms ("Tension, irritability, or nervousness," "feeling depressed," and "unusual tiredness, fatigue, or drowsiness") in summer was significantly higher than those in winter. The prevalence of the symptoms of "tired or strained eyes" in summer was also higher than that in winter. However, the prevalence of symptoms of "sore or dry 
Table 5 Association between weekly building-related symptoms and workplace conditions in the last 4 weeks (Model 3)

\begin{tabular}{|c|c|c|c|c|}
\hline \multirow[t]{2}{*}{ Variable factors $^{a}$} & $\begin{array}{l}\text { Eye irritation } \\
\text { OR }(95 \% \mathrm{Cl})\end{array}$ & \multirow{2}{*}{$\begin{array}{l}\text { General symptoms } \\
\text { OR }(95 \% \mathrm{Cl}) \\
N=2502\end{array}$} & \multirow{2}{*}{$\begin{array}{l}\text { Upper respiratory } \\
\text { OR }(95 \% \mathrm{Cl}) \\
N=2483\end{array}$} & \multirow{2}{*}{$\begin{array}{l}\text { Skin symptoms } \\
\text { OR }(95 \% \mathrm{Cl}) \\
N=2684\end{array}$} \\
\hline & $N=2587$ & & & \\
\hline Too much air movement & $0.78(0.55-1.09)$ & $0.95(0.69-1.32)$ & $1.00(0.66-1.53)$ & $0.61(0.31-1.23)$ \\
\hline Too little air movement & $1.00(0.87-1.15)$ & $1.31(1.14-1.50)^{* *}$ & $1.23(1.03-1.49)^{*}$ & $1.13(0.84-1.54)$ \\
\hline Too hot & $1.09(0.94-1.26)$ & $1.15(1.00-1.33)$ & $1.26(1.03-1.54)^{*}$ & $1.13(0.80-1.60)$ \\
\hline Varying room temperature & $1.16(0.98-1.36)$ & $1.00(0.85-1.18)$ & $1.03(0.82-1.29)$ & $1.11(0.77-1.60)$ \\
\hline Too cold & $0.97(0.80-1.18)$ & $1.38(1.13-1.68)^{* *}$ & $1.12(0.87-1.44)$ & $0.91(0.61-1.35)$ \\
\hline Air too humid & $1.21(1.02-1.45)^{*}$ & $1.12(0.94-1.34)$ & $0.89(0.69-1.13)$ & $0.98(0.67-1.43)$ \\
\hline Air too dry & $1.49(1.25-1.77)^{* *}$ & $1.23(1.02-1.47)^{*}$ & $1.78(1.44-2.19)^{* *}$ & $2.56(1.83-3.57)^{* *}$ \\
\hline Static electricity & $1.38(1.01-1.90)^{*}$ & $1.08(0.76-1.53)$ & $0.68(0.43-1.05)$ & $1.10(0.63-1.90)$ \\
\hline Noise & $1.23(0.99-1.52)$ & $1.50(1.22-1.84)^{* *}$ & $1.34(1.03-1.76)^{*}$ & $1.22(0.81-1.86)$ \\
\hline Airflow from air conditioner & $1.11(0.96-1.28)$ & $1.11(0.96-1.28)$ & $1.13(0.93-1.36)$ & $0.89(0.64-1.25)$ \\
\hline Odors from air conditioner & $1.07(0.83-1.39)$ & $1.01(0.77-1.32)$ & $0.94(0.67-1.31)$ & $1.25(0.75-2.09)$ \\
\hline Mold odor & $0.90(0.66-1.24)$ & $0.84(0.61-1.16)$ & $1.09(0.75-1.58)$ & $0.64(0.35-1.17)$ \\
\hline Dust and dirt & $1.08(0.88-1.32)$ & $1.10(0.90-1.34)$ & $1.22(0.96-1.55)$ & $0.82(0.55-1.22)$ \\
\hline Tobacco smoke odor & $1.22(1.03-1.43)^{*}$ & $1.23(1.04-1.45)^{*}$ & $1.19(0.97-1.46)$ & $1.23(0.88-1.70)$ \\
\hline Unpleasant chemical odor & $1.03(0.69-1.56)$ & $0.87(0.57-1.32)$ & $1.56(1.01-2.42)^{*}$ & $2.52(1.44-4.42)^{* *}$ \\
\hline Unpleasant other odor ${ }^{b}$ & $1.19(1.00-1.42)$ & $1.37(1.15-1.64)^{* *}$ & $1.20(0.96-1.50)$ & $1.55(1.10-2.19)^{*}$ \\
\hline
\end{tabular}

Values are expressed as adjusted odds ratios $(95 \% \mathrm{Cl})$ for participants with complete data. Values are adjusted for personal factors and job stressors with $p<0.2$ in univariate analyses using multivariate regression analysis. Ref. $=$ referent. Significant at ${ }^{*} p<0.05,{ }^{* *} p<0.01$. Text in parentheses reflects case groups

${ }^{a}$ Four levels of response are 1) never, 2) 1-3 days, 3) 1-3 days per week, and 4) every or almost every workday

${ }^{b}$ For example, body odor, food odor, or perfume

throat" and symptoms of "dry or flushed facial skin" in summer was lower than that in winter. In addition, for comparison between winter and summer using potential risk factors (personal factors, work environment, workplace conditions in the last 4 weeks, and job stressors), logistic regression analyses were conducted adding the seasonal factor (summer and winter) to the combined data of summer and winter using the same method as that used in Model 4. The adjusted ORs (summer) of weekly BRSs in terms of eye irritation, general symptoms, upper respiratory symptoms, and skin symptoms were 2.05 (95\% CI, 1.66-2.54; $p<0.001), 1.64$ (95\% CI, 1.34-2.01; $p<0.001$ ), 1.06 (95\% CI, 0.79-1.42; $p=0.699$ ), and 0.70 (95\% CI, 0.47-1.05; $p=0.084$ ), respectively.

Significant risk factors associated with weekly BRSs in the final model in winter and summer are shown in Table 8. Excessive work was common risk factor of eye irritation and general symptoms in both seasons. Strong interpersonal conflict and low work satisfaction were also common risk factors for general symptoms.

In the work environment, carpeting, uncomfortable seating, and increased use of odorous chemicals were common risk factors for eye irritation in both seasons. Poor lighting was significant risk factor of eye irritation in winter but often reflection or glare was a risk factor in summer. Carpeting and uncomfortable seating were significant risk factors for general and upper respiratory symptoms in summer but such factors were not significant in winter. Particularly, a recently painted wall was a significant risk factor for upper respiratory symptoms in summer and a crowded workplace was a significant risk factor for general and upper respiratory symptoms in winter.

In the risk factors related to indoor air quality, dryness of air was a common risk factor for BRSs in both seasons, but humidity was the only significant risk factor for general symptoms in summer. In particular, unpleasant chemical odors were a significant risk factor for upper respiratory and skin symptoms in summer but not in winter. Noise, dust and dirt, and unpleasant odors (e.g., body odors, food odors, or perfume) were significant risk factors for some BRSs in both seasons.

\section{Discussion}

The U.S. Environmental Protection Agency (USEPA) conducted a Building Assessment Survey Evaluation (BASE) study in 100 office buildings in the United States, the sites of work of 4326 office workers, in the 1990s [40]. The questionnaire used in our survey comprised the USEPA questionnaire [33] used in the BASE study. Therefore, the prevalence estimated in our study can be exactly compared with the prevalence estimated in the BASE study. The BASE study identified the three most prevalent BRSs as "tired or strained eyes" (22\%), "dry, itching, or irritated eyes" 
Table 6 Final models for the association between weekly building-related symptoms and all variables (Model 4)

\begin{tabular}{|c|c|c|c|c|}
\hline \multirow[t]{2}{*}{ Variable factors } & $\begin{array}{l}\text { Eye irritation } \\
\text { OR }(95 \% \mathrm{Cl})\end{array}$ & $\begin{array}{l}\text { General symptoms' } \\
\text { OR }(95 \% \mathrm{Cl})\end{array}$ & $\begin{array}{l}\text { Upper respiratory } \\
\text { OR }(95 \% \mathrm{Cl})\end{array}$ & $\begin{array}{l}\text { Skin symptoms } \\
\text { OR }(95 \% \mathrm{Cl})\end{array}$ \\
\hline & $N=2330$ & $N=2275$ & $N=2260$ & $N=2436$ \\
\hline \multicolumn{5}{|l|}{ Personal } \\
\hline Gender (female) & $1.67(1.23-2.28)^{* *}$ & $1.80(1.36-2.38)^{* *}$ & $2.27(1.48-3.48)^{* *}$ & $3.12(1.48-6.59)^{* *}$ \\
\hline \multicolumn{5}{|l|}{ Age } \\
\hline $10-19$ & - & $1.96(0.19-19.71)$ & - & - \\
\hline $20-29$ & - & $3.24(1.68-6.23)^{* *}$ & - & - \\
\hline $30-39$ & - & $2.16(1.16-4.00)^{*}$ & - & - \\
\hline $40-49$ & - & $1.66(0.89-3.11)$ & - & - \\
\hline $50-59$ & - & $1.35(0.71-2.58)$ & - & - \\
\hline$\geq 60$ & - & Ref. & - & - \\
\hline$p$ for trend & - & $<0.001$ & - & - \\
\hline Contact lens use & $1.59(1.20-2.10)^{* *}$ & - & $1.73(1.16-2.57)^{* *}$ & - \\
\hline Pet ownership (Cat) & & & - & $2.86(1.28-6.43)^{*}$ \\
\hline \multicolumn{5}{|l|}{ Work environment } \\
\hline No. of people in office ${ }^{a}$ & $1.19(1.03-1.39)^{*}$ & - & - & - \\
\hline \multicolumn{5}{|l|}{ Work station } \\
\hline Floor carpet (with) & $1.44(1.07-1.95)^{*}$ & $1.53(1.15-2.05)^{* *}$ & $1.74(1.10-2.75)^{*}$ & - \\
\hline Reflection or glare in vision ${ }^{b}$ & $1.25(1.07-1.45)^{* *}$ & $1.32(1.13-1.55)^{* *}$ & - & - \\
\hline Chair comfort $^{c}$ & $1.37(1.13-1.67)^{* *}$ & $1.35(1.11-1.63)^{* *}$ & $1.74(1.34-2.27)^{* *}$ & - \\
\hline Work with computer & $5.51(1.62-18.73)^{* *}$ & - & & \\
\hline Use of odorous chemicals ${ }^{d}$ & $1.11(1.02-1.21)^{*}$ & - & - & - \\
\hline \multicolumn{5}{|l|}{ Change in workplace ${ }^{e}$} \\
\hline Painted wall & & & $4.72(1.57-14.22)^{* *}$ & \\
\hline \multicolumn{5}{|c|}{ Workplace conditions in last 4 weeks ${ }^{f}$} \\
\hline Too little air movement & - & $1.37(1.21-1.56)^{* *}$ & $1.26(1.05-1.50)^{*}$ & - \\
\hline Varying room temperature & $1.23(1.07-1.42)^{* *}$ & - & - & - \\
\hline Too cold & - & $1.45(1.21-1.73)^{* *}$ & - & - \\
\hline Air too humid & - & $1.20(1.02-1.43)^{*}$ & - & - \\
\hline Air too dry & $1.46(1.24-1.72)^{* *}$ & - & $1.76(1.44-2.14)^{* *}$ & $2.71(2.10-3.51)^{* *}$ \\
\hline Static electricity & - & - & - & - \\
\hline Noise & $1.29(1.05-1.59)^{*}$ & $1.54(1.25-1.88)^{* *}$ & $1.41(1.09-1.82)^{* *}$ & - \\
\hline Dust and dirt & - & - & $1.26(1.00-1.58)^{*}$ & - \\
\hline Tobacco smoke odor & $1.21(1.02-1.43)^{*}$ & - & - & - \\
\hline Unpleasant chemical odor & - & - & $1.96(1.24-3.08)^{* *}$ & $2.60(1.63-4.15)^{* *}$ \\
\hline Unpleasant other odor ${ }^{9}$ & $1.22(1.02-1.45)^{*}$ & $1.35(1.14-1.61)^{* *}$ & - & \\
\hline \multicolumn{5}{|l|}{ Job stressors } \\
\hline Amount of work ${ }^{h}$ & $1.34(1.19-1.51)^{* *}$ & $1.38(1.23-1.55)^{* *}$ & $1.25(1.06-1.46)^{* *}$ & \\
\hline Mental workload ${ }^{h}$ & - & - & & \\
\hline Physical overload ${ }^{i}$ & $0.70(0.59-0.83)^{* *}$ & - & - & \\
\hline Interpersonal conflict ${ }^{h}$ & - & $1.42(1.21-1.65)^{* *}$ & - & - \\
\hline Job control ${ }^{h}$ & - & $0.80(0.70-0.92)^{* *}$ & - & - \\
\hline Skill utilization' & - & - & - & - \\
\hline Job suitability ${ }^{k}$ & - & & - & \\
\hline
\end{tabular}


Table 6 Final models for the association between weekly building-related symptoms and all variables (Model 4) (Continued)

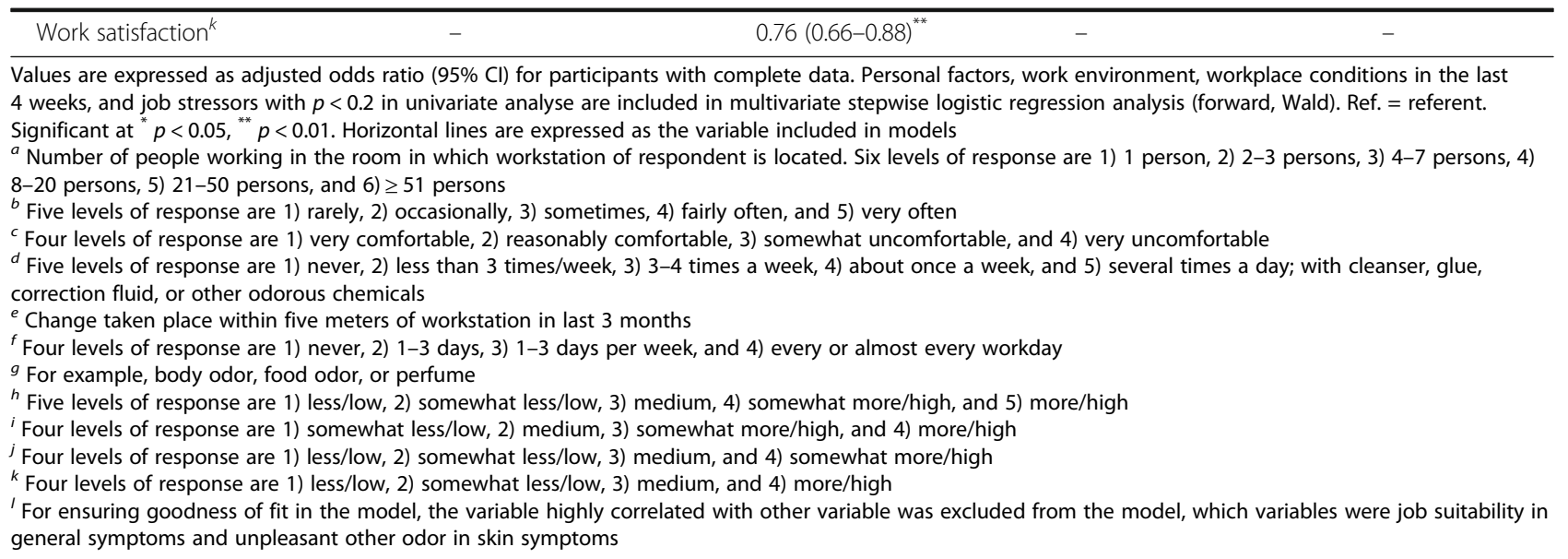

(19\%), and "pain or stiffness in the back, shoulders, or neck" (17\%). The lowest prevalence was associated with "shortness of breath and wheezing" (2\%). In our study, the three most prevalent BRSs during winter were "tension, irritability, or nervousness" (8.8\%), "tired or strained eyes" (8.0\%), and "dry, itching, or irritated eyes" (7.1\%). The prevalence of "tension, irritability, or nervousness," "tired or strained eyes," and "dry, itching, or irritated eyes" during summer were $11.6 \%, 10.2 \%$, and $7.5 \%$, respectively. The lowest prevalence was "wheezing" $(0.2 \%)$ in both seasons. In both BASE and our studies, the prevalence of BRSs followed approximately the same rank ordering. Compared with the BASE study, overall prevalence was lower in our studies. However, the prevalence of "feeling depressed" in both

Table 7 Comparison of prevalence of weekly building-related symptoms between winter and summer

\begin{tabular}{|c|c|c|c|c|}
\hline \multirow[t]{2}{*}{ Symptoms } & \multicolumn{2}{|c|}{ Prevalence $^{a}(\%)$} & \multicolumn{2}{|l|}{ Summer (vs. winter) } \\
\hline & Winter & Summer & Crude OR (95\% Cl) & Adjusted $\mathrm{OR}^{\mathrm{b}}(95 \% \mathrm{Cl})$ \\
\hline Tension, irritability, or nervousness & 8.77 & 11.58 & $1.36(1.15-1.61)^{* *}$ & $1.30(1.09-1.55)^{* *}$ \\
\hline Tired or strained eyes & 7.99 & 10.21 & $1.31(1.10-1.57)^{* *}$ & $1.27(1.05-1.53)^{*}$ \\
\hline Dry, itching, or irritated eyes & 7.15 & 7.52 & $1.06(0.87-1.28)$ & $1.01(0.82-1.23)$ \\
\hline Feeling depressed & 5.12 & 6.83 & $1.36(1.10-1.68)^{* *}$ & $1.31(1.05-1.63)^{*}$ \\
\hline Unusual tiredness, fatigue, or drowsiness & 4.71 & 6.39 & $1.38(1.11-1.72)^{* *}$ & $1.36(1.08-1.70)^{* *}$ \\
\hline Sore or dry throat & 5.69 & 3.70 & $0.64(0.50-0.81)^{* *}$ & $0.56(0.43-0.72)^{* *}$ \\
\hline Headache & 2.35 & 2.65 & $1.13(0.82-1.56)$ & $1.06(0.76-1.47)$ \\
\hline Difficulty remembering things or concentration & 1.45 & 2.19 & $1.52(1.03-2.23)^{*}$ & $1.46(0.98-2.17)$ \\
\hline Sneezing & 1.82 & 1.84 & $1.01(0.69-1.47)$ & $0.97(0.65-1.43)$ \\
\hline Cough & 1.55 & 1.24 & $0.80(0.52-1.23)$ & $0.73(0.47-1.14)$ \\
\hline Dry or flushed facial skin & 3.18 & 1.21 & $0.37(0.25-0.55)^{* *}$ & $0.33(0.22-0.49)^{* *}$ \\
\hline Stuffy or runny nose, or sinus congestion & 1.71 & 1.18 & $0.68(0.44-1.05)$ & $0.67(0.43-1.04)$ \\
\hline Hands dry, Itching, red skin & 1.43 & 1.11 & $0.78(0.49-1.22)$ & $0.68(0.42-1.08)$ \\
\hline Dizziness or lightheadedness & 0.74 & 1.09 & $1.48(0.87-2.53)$ & $1.38(0.80-2.36)$ \\
\hline Nausea or upset stomach & 0.86 & 1.09 & $1.27(0.76-2.11)$ & $1.10(0.65-1.84)$ \\
\hline Scaling/itching scalp or ears & 1.01 & 0.78 & $0.77(0.45-1.31)$ & $0.68(0.39-1.16)$ \\
\hline Shortness of breath & 0.27 & 0.50 & $1.84(0.80-4.20)$ & $1.58(0.69-3.64)$ \\
\hline Chest tightness & 0.52 & 0.50 & $0.97(0.48-1.95)$ & $0.84(0.40-1.75)$ \\
\hline Wheezing & 0.21 & 0.23 & $1.10(0.39-3.14)$ & $1.14(0.38-3.40)$ \\
\hline
\end{tabular}

${ }^{a}$ A participant experienced the symptom at least 1 day per week in the last 4 weeks that improved when the participant was away from the building. Significant at ${ }^{*} p<0.05,{ }^{* *} p<0.01$

${ }^{b}$ Mantel-Haenszel test was carried out to estimate the adjusted odds ratio (OR) and the $95 \%$ confidence interval (95\% Cl) for the BRSs with/without adjustment for potential confounders, including age, gender, and job, which showed $p<0.2$ in univariate analyses. Tarone test showed $p>0.05$ in all symptoms 
Table 8 Significant risk factors associated with weekly building-related symptoms in final model in winter $(N=3335)$ and summer $(N=3024)$

\begin{tabular}{|c|c|c|c|}
\hline \multirow[t]{2}{*}{ Symptoms and seasons } & \multicolumn{3}{|l|}{ Significant risk factors } \\
\hline & Job stressor & Work environment & Indoor air quality \\
\hline \multicolumn{4}{|l|}{ Eye irritation } \\
\hline Winter & $\begin{array}{l}\text { - Excessive work } \\
\text { - Adequate skill utilization }\end{array}$ & $\begin{array}{l}\text { - Carpeting } \\
\text { - Poor lighting } \\
\text { - Uncomfortable seating } \\
\text { - Often use of odorous chemicals }{ }^{a}\end{array}$ & $\begin{array}{l}\text { - Too cold } \\
\text { - Too dry } \\
\text { - Strong static electricity } \\
\text { - Airflow from air conditioner } \\
\text { - Dust and dirt }\end{array}$ \\
\hline Summer & $\begin{array}{l}\text { - Excessive work } \\
\text { - Low physical overload }\end{array}$ & $\begin{array}{l}\text { - Crowded workplace } \\
\text { - Carpeting } \\
\text { - Often reflection or glare in vision } \\
\text { - Uncomfortable seating } \\
\text { - Computer work } \\
\text { - Often use of odorous chemicals }\end{array}$ & $\begin{array}{l}\text { - Varying room temperature } \\
\text { - Too dry } \\
\text { - Noise } \\
\text { - Tobacco smoke odor } \\
\text { - Unpleasant other odor }\end{array}$ \\
\hline \multicolumn{4}{|l|}{ General symptoms } \\
\hline Winter & $\begin{array}{l}\text { - Excessive work } \\
\text { - High mental workload } \\
\text { - Strong interpersonal conflict } \\
\text { - Low job suitability } \\
\text { - Low work satisfaction }\end{array}$ & - Crowded workplace & $\begin{array}{l}\text { - Too little air movement } \\
\text { - Varying room temperature } \\
\text { - Too cold } \\
\text { - Too dry } \\
\text { - Noise } \\
\text { - Dust and dirt } \\
\text { - Unpleasant other odor }\end{array}$ \\
\hline Summer & $\begin{array}{l}\text { - Excessive work } \\
\text { - Strong interpersonal conflict } \\
\text { - Low job control } \\
\text { - Low work satisfaction }\end{array}$ & $\begin{array}{l}\text { - Carpeting } \\
\text { - Reflection or glare in vision } \\
\text { - Uncomfortable seating }\end{array}$ & $\begin{array}{l}\text { - Too little air movement } \\
\text { - Too cold } \\
\text { - Too humid } \\
\text { - Noise } \\
\text { - Unpleasant other odor }\end{array}$ \\
\hline \multicolumn{4}{|l|}{ Upper respiratory } \\
\hline Winter & - Strong interpersonal conflict & $\begin{array}{l}\text { - Crowded workplace } \\
\text { - Installation of bubble jet printer }\end{array}$ & $\begin{array}{l}\text { - Too dry } \\
\text { - Dust and dirt } \\
\text { - Unpleasant other odor }\end{array}$ \\
\hline Summer & - Excessive work & $\begin{array}{l}\text { - Carpeting } \\
\text { - Uncomfortable seating } \\
\text { - Recent painted wall }\end{array}$ & $\begin{array}{l}\text { - Too little air movement } \\
\text { - Too dry } \\
\text { - Noise } \\
\text { - Dust and dirt } \\
\text { - Unpleasant chemical odor }\end{array}$ \\
\hline \multicolumn{4}{|l|}{ Skin symptoms } \\
\hline Winter & - Low work satisfaction & & $\begin{array}{l}\text { - Varying room temperature } \\
\text { - Too dry } \\
\text { - Noise } \\
\text { - Airflow from air conditioner } \\
\text { - Dust and dirt }\end{array}$ \\
\hline Summer & & & $\begin{array}{l}\text { - Too dry } \\
\text { - Unpleasant chemical odor }\end{array}$ \\
\hline
\end{tabular}

a Cleaning substance, adhesives, correction liquid, or odor products, etc

b Body odor, food odor, or perfume, etc

seasons of our studies was higher than that of the BASE study. The prevalence of "tension, irritability, or nervousness" in summer, and that of "sore or dry throat" in winter, was close to the prevalence of the BASE study. Prevalence obtained from the present study were also substantially lower than those of a recent study [10]. In Japan, the Law for Maintenance of Sanitation in Buildings was enacted in 1970 and the Building Sanitation Management Standards were also established in 1970. Those standards might be effective for prevention of BRSs.
BRSs were common, with approximately one in four persons having at least one BRS. Their prevalence in summer $(27.8 \%)$ was slightly higher than that in winter (24.9\%) [28]. The prevalence of eye irritation, general symptoms, upper respiratory symptoms, lower respiratory symptoms, and skin symptoms was $12.1 \%, 14.4 \%$, $8.9 \%, 0.8 \%$, and $4.5 \%$, respectively, in the study in winter [28] and $14.1 \%, 18.3 \%, 6.7 \%, 0.9 \%$, and $2.2 \%$, respectively, in summer. Overall, general symptoms therefore had the highest prevalence, followed by eye irritation and upper respiratory symptoms in both winter and summer. 
Lower respiratory symptoms had the lowest prevalence in both seasons.

Regarding the risk factors of BRSs, dryness of air was an important significant risk factor in both seasons in this study. This may influence the high prevalence of BRSs related to mucosal dryness. In our study, the prevalence of "dry, itching, or irritated eyes" was high, followed "tension, irritability, or nervousness" and "tired or strained eyes" in both seasons. Several studies have reported that the dryness of nose, throat, eyes, and skin was improved by adequate humidification [41-44]. Low humidity was associated with increased eye irritation and the alteration of the precorneal tear film (PTF) [26]. A visual display unit (VDU) can be used for computer work, as a monitor may exacerbate these effects. Our study indicated that computer work had a strongly significant association with eye irritation in summer.

Our study indicated that humidity was significantly associated with general symptoms in summer. Although summer in Japan is hot and humid, a campaign named Cool Biz has been implemented by the Japanese government since 2005, recommending raising the set points during summer to $28{ }^{\circ} \mathrm{C}$ and wearing lighter clothing [45]. At high temperatures, the degree of discomfort can be heavily influenced by humidity level [46]. Air-conditioning system with humidity control could create a comfortable work environment, even at temperatures as high as $30{ }^{\circ} \mathrm{C}$, as compared to temperature control alone [47]. Adequate indoor humidity control will reduce general symptoms in hot and humid climate regions.

Recently painted walls and unpleasant chemical odors in summer were significantly associated with BRSs. Those effects are likely to be found in summer, as concentrations of specific volatile organic compounds may be especially elevated in a hot season. Higher indoor concentrations of aromatic and aliphatic hydrocarbons were found more often during winter in existing buildings, while the concentrations of carbonyl compounds, organophosphorus compounds, ammonia, and ozone, which include strong irritants to the upper respiratory tract and skin, were higher during summer [29-31]. Although a moderate association between upper respiratory symptoms, dry throat, and irritability related to buildings and concentrations of total volatile organic compound in the workplace have been suggested [48], studies reported that no consistent association between BRSs and indoor exposure levels of individual volatile organic compound or total volatile organic compound were found $[49,50]$. No measurements of indoor pollutants were conducted in the present study. Future observational research during a hot season would provide valuable information for understanding those effects.
Noise, dust and dirt were significant risk factors for some BRSs in both seasons. The associations have been reported in the previous studies $[10,16,51]$. The presence of acoustical insulation and/or sound absorption materials increased overall building comfort and cleaning the work area in the morning before a workday began decreased both BRSs and overall building discomfort, compared to cleaning it in the evening after work [10]. However, further research is needed to clarify the reported relationships. In particular, noise was significantly associated with general symptoms, eye irritation, and upper respiratory symptoms during summer in the present study. Noise can involve general symptoms but may not be a cause of mucosal eye irritation or mucosal upper respiratory dysfunction. Persons with a high level of general symptom may be more sensitive to eye and upper respiratory mucosal dysfunction, and such dysfunction could trigger more general symptoms. Therefore, eye irritation and upper respiratory symptoms might be induced as a common sense with general symptoms. BRS is known as one of the medically unexplained symptoms including conditions such as multiple chemical sensitivity, chronic fatigue syndrome, fibromyalgia, and the like. BRS is characterized by subjective responses to nonspecific conditions associated with the use of a building and due to causes resulting from the complex interaction of several factors, such as exposure to indoor chemical and biological pollutants, indoor physical conditions, exposure to occupational stress, and individual susceptibility [52]. Investigation of involvement of psychosocial factors, including personality traits, personal circumstances, and individual perceptions is required.

General symptoms, including "tension, irritability, or nervousness," "feeling depressed," "unusual tiredness, fatigue, or drowsiness," and so forth were significantly associated with excessive work, strong interpersonal conflict, and low work satisfaction in both seasons. A reduction in psychological distress related to work throughout the year is needed.

Our study had several limitations. We used a crosssectional study design. The cross-sectional nature of the study limits any causal inferences and may be subject to a recall bias. Several environmental reports from respondents are subjective, and the resulting inaccuracies may have resulted in a bias. This is also true of the subjective, self-reported health outcome assessments used in this study. The office managers selected all office workers when 10 or less office workers in their office met our selection criteria, but otherwise, managers arbitrarily selected 15 office workers at a maximum that met the criteria. The proportion of participants that worked in offices with no more than 20 employees was $71.0 \%$ (72.6\% in winter). Although office workers who met the 
exclusion criteria will have been included in that number, we cannot exclude selection bias. Thus, it is probably less likely that office workers with symptoms rather than those without symptoms tended to be selected as participants by the managers, and vice versa. The prevalence of BRSs obtained in this study would include such uncertainty. However, it is probably less likely that the selection bias severely influenced the strength of the associations between BRSs and the possible risk factors as well as seasonal comparisons of prevalence and risk factors of BRSs between winter and summer. Office workers suffering from BRSs may avoid working overtime, which may have underestimated the prevalence and risks of extensive overtime. Finally, we analyzed mass variable factors that could introduce a systematic statistical bias. We therefore performed a number of statistical analyses (four models, two stepwise procedures of Wald and likelihood ratio), and the results were similar for the different models used; thus, it is less likely that the analysis results of risk factors were affected by a particular statistical model or the large number of statistical tests performed.

\section{Conclusions}

BRSs were common in this nationwide survey, with approximately one in four persons having at least one BRS in both winter and summer. Analyses suggested that adequate humidity control and managing job stress throughout the year will reduce BRSs. Physical risk factors such as recently painted walls and unpleasant chemical odors in summer and noise, dust and dirt, and unpleasant odors including body or food odors were significant risk factors of some BRSs in both the seasons. Improvements of the physical environmental qualities in the office environment are important. Moreover, the prevention of BRSs should not only depend on physical measures but also involve comprehensive interventions to improve psychosocial well-being and mental health in office workers. Our results suggest intervention points of physical and psychosocial environment for office managers and health professionals.

\section{Additional file}

Additional file 1: Table S1. Univariate analysis for the association with weekly building-related symptoms. Table $\mathbf{S} 2$ Number of cases by variable factors for weekly building-related symptoms. (DOCX $59 \mathrm{~kb}$ )

\section{Acknowledgments}

We would like to extend our sincere thanks to Takayuki Nakamura, Tomoko Shimodaira, and the staff of the Japan Building Maintenance Association for their help in conducting this survey. We thank Daichi Takano and Yuma Nakagawa (formerly of the Department of Architecture, College of Science and Technology, Nihon University) for their assistance in the laboratory. We also thank all the participants for their collaboration.

\section{Funding}

This study was financially supported by a Grant-in-Aid for Health and Labour Sciences Research Grant (H23-health/crisis-009) provided by the Japanese Ministry of Health, Labour and Welfare.

Availability of data and material

All data generated or analyzed during this study are included in this published article and its Additional file 1.

\section{Authors' contributions}

The five authors are justifiably credited with authorship, according to the authorship criteria. In detail: KA—conception, design, acquisition of data, analysis and interpretation of data, drafting of the manuscript, final approval given; $\mathrm{Kl}$-conception, design, critical revision of manuscript, final approval given; NK-design, acquisition of data, critical revision of manuscript, final approval given; UY — design, acquisition of data, critical revision of manuscript, final approval given; $\mathrm{HO}$ — conception, design, acquisition of data, critical revision of manuscript, final approval given.

\section{Competing interests}

The authors declare that there is no conflict of interest.

\section{Consent for publication}

Not applicable.

\section{Ethics approval and consent to participate}

The ethics committee for human research at the National Institute of Public Health (Wako, Japan) (NIPH-IBRA \#12003) approved this study. Furthermore, the study was completed in accordance with the Declaration of Helsinki.

\section{Author details}

'Department of Environmental Medicine and Behavioral Science, Kindai University Faculty of Medicine, 377-2 Ohnohigashi, Osakasayama, Osaka 589-8511, Japan. ${ }^{2}$ Department of Architecture, College of Science and Technology, Nihon University, 8-14 Kanda-Surugadai 1-chome, Chiyoda-ku, Tokyo 101-8308, Japan. ${ }^{3}$ Department of Mechanical and Environmental Informatics, Graduate School of Information Science and Engineering, Tokyo Institute of Technology, 2-12-1 Ookayama, Meguro-ku, Tokyo 152-8550, Japan. ${ }^{4}$ Department of Architecture, School of Architecture, Kogakuin University, 1-24-2 Nishi-Shinjuku, Shinjuku-ku, Tokyo 163-8677, Japan. ${ }^{5}$ Department of Environmental Health, National Institute of Public Health, 2-3-6 Minami, Wako, Saitama 351-0197, Japan.

Received: 17 January 2017 Accepted: 1 February 2017 Published online: 12 April 2017

\section{References}

1. Redlich CA, Sparer J, Cullen MR. Sick-building syndrome. Lancet. 1997;349:1013-6.

2. Finnegan MJ, Pickering CAC, Burge PS. The sick building syndrome: prevalence studies. BMJ. 1984;289:1573-5.

3. Burge PS. Sick building syndrome. Occup Environ Med. 2004;61:185-90.

4. Norbäck D, Torgén M, Edling C. Volatile organic compounds, respirable dust, and personal factors related to prevalence and incidence of sick building syndrome in primary schools. Br J Ind Med. 1990:47:733-41.

5. Runeson R, Wahlstedt K, Wieslander G, Norbäck D. Personal and psychosocial factors and symptoms compatible with sick building syndrome in the Swedish workforce. Indoor Air. 2006;16:445-53.

6. Runeson R, Norbäck D, Klinteberg B, Edling C. The influence of personality, measured by the Karolinska Scales of Personality (KSP), on symptoms among subjects in suspected sick buildings. Indoor Air. 2004;14:394-404.

7. Fisk WJ, Mirer AG, Mendell MJ. Quantitative relationship of sick building syndrome symptoms with ventilation rates. Indoor Air. 2009;19:159-65.

8. Mendell MJ, Lei-Gomez Q, Mirer AG, Seppänen O, Brunner G. Risk factors in heating, ventilating, and air-conditioning systems for occupant symptoms in US office buildings: the US EPA BASE study. Indoor Air. 2008;8:301-16.

9. Apter A, Bracker A, Hodgson M, Sidman J, Leung WY. Epidemiology of the sick building syndrome. J Allergy Clin Immunol. 1994;94:277-88.

10. Bluyssen PM, Roda C, Mandin C, Fossati S, Carrer P, de Kluizenaar Y, et al. Self-reported health and comfort in 'modern' office buildings: first results from the European OFFICAIR study. Indoor Air. 2016;26:298-317. 
11. Fisk WJ, Lei-Gomez Q, Mendell MJ. Meta-analyses of the associations of respiratory health effects with dampness and mold in homes. Indoor Air. 2007;17:284-96

12. Maddalena R, Mendell MJ, Eliseeva K, Chan WR, Sullivan DP, Russell M, et al. Effects of ventilation rate per person and per floor area on perceived air quality, sick building syndrome symptoms, and decision-making. Indoor Air. 2015;25:362-70

13. Magnavita N. Work-related symptoms in indoor environments: a puzzling problem for the occupational physician. Int Arch Occup Environ Health. 2015;88:185-96.

14. Marmot AF, Stafford JM, Stansfeld SA, Warwick E, Marmot MG. Building health: an epidemiological study of "sick building syndrome" in the Whitehall II study. Occup Environ Med. 2006;63:283-9.

15. Norbäck D, Nordström K. Sick building syndrome in relation to air exchange rate, $\mathrm{CO}(2)$, room temperature and relative air humidity in university computer classrooms: an experimental study. Int Arch Occup Environ Health. 2008;82:21-30.

16. Niven R, Fletcher A, Pickering C, Faragher E, Potter I, Booth W, et al. Building sickness syndrome in healthy and unhealthy buildings: an epidemiological and environmental assessment with cluster analysis. Occup Environ Med. 2000:57:627-34.

17. Ruotsalainen R, Jaakkola N, Jaakkola JJ. Dampness and molds in day-care centers as an occupational health problem. Int Arch Occup Environ Health. 1995;66:369-74.

18. Teeuw KB, Vandenbroucke-Grauls CM, Verhoef J. Airborne gram-negative bacteria and endotoxin in sick building syndrome. A study in Dutch governmental office buildings. Arch Intern Med. 1994;154:2339-45.

19. Zhang X, Sahlberg B, Wieslander G, Janson C, Gislason T, Norbäck D. Dampness and moulds in workplace buildings: associations with incidence and remission of sick building syndrome (SBS) and biomarkers of inflammation in a 10 year follow-up study. Sci Total Environ. 2012:430:75-81.

20. Chao HJ, Schwartz J, Milton DK, Burge HA. The work environment and workers' health in four large office buildings. Environ Health Perspect. 2003;111:1242-8.

21. Hansen AM, Meyer HW, Gyntelberg F. Building-related symptoms and stress indicators. Indoor Air. 2008;18:440-6.

22. Kinman G, Griffin M. Psychosocial factors and gender as predictors of symptoms associated with sick building syndrome. Stress Health. 2008;24:165-71.

23. Runeson R, Norbäck D. Sick building syndrome (SBS) and sick house syndrome (SHS) in relation to psychosocial stress at work in the Swedish workforce. Int Arch Occup Environ Health. 2013;86:915-22.

24. Azuma K, Ikeda K, Osawa H, Kagi N, Yanagi U, Saito H, et al. Actual status of environmental sanitation and building maintenance in Japan. Trans Soc Heating Air-Conditioning Sanitary Eng Japan. 2012;179:19-26 (in Japanese with English abstract).

25. Wolkoff P. "Healthy" eye in office-like environments. Environ Int. 2008:34:1204-14.

26. Wolkoff P. Ocular discomfort by environmental and personal risk factors altering the precorneal tear film. Toxicol Lett. 2010;199:203-12.

27. Khatri M, Bello D, Gaines P, Martin J, Pal AK, Gore R, et al. Nanoparticles from photocopiers induce oxidative stress and upper respiratory tract inflammation in healthy volunteers. Nanotoxicology. 2013;7:1014-27.

28. Azuma K, Ikeda K, Kagi N, Yanagi U, Osawa H. Prevalence and risk factors associated with nonspecific building-related symptoms in office employees in Japan: relationships between work environment, Indoor Air Quality, and occupational stress. Indoor Air. 2015;25:499-511.

29. Ohura T, Amagai T, Senga Y, Fusaya M. Organic air pollutants inside and outside residences in Shimizu, Japan: levels, sources and risks. Sci Tota Environ. 2006;366:485-99.

30. Pegas PN, Alves CA, Evtyugina MG, Nunes T, Cerqueira M, Franchi M, et al. Seasonal evaluation of outdoor/indoor air quality in primary schools in Lisbon. J Environ Monit. 2011:13:657-67.

31. Uchiyama S, Tomizawa T, Tokoro A, Aoki M, Hishiki M, Yamada T, et al. Gaseous chemical compounds in indoor and outdoor air of 602 houses throughout Japan in winter and summer. Environ Res. 2015;137:364-72.

32. Azuma K, Ikeda K, Osawa H, Kagi N, Yanagi U, Shimodaira T. Questionnaire survey on indoor air quality and maintenance of sanitary environment in buildings. Proceedings of the 12th International Conference on Indoor Air Quality and Climate 2011, Austin, USA, Paper 248, 6 p.
33. USEPA. A standardized EPA protocol for characterizing indoor air quality in large office buildings. Washington: Environmental Protection Agency; 2003.

34. Andersson K. Epidemiological approach to indoor air problems. Indoor Air. 1998:8 Suppl 4:32-9.

35. Shimomitsu T, Ohno H, Maruta T, Tanigawa T. Investigation research report concerning prevention of disease related to work in 1997 the Ministry of Labor: III Stress Measurement Research Group Report. Tokyo: Tokyo Medical University; 2000. p. 101-69. in Japanese.

36. Wada K, Sairenchi T, Haruyama Y, Taneichi H, Ishikawa Y, Muto T. Relationship between the onset of depression and stress response measured by the brief job stress questionnaire among Japanese employees: a cohort study. PLoS One. 2013;8:e56319.

37. Dormann CF, Elith J, Bacher S, Buchmann C, Carl G, Carré G, et al. Collinearity: a review of methods to deal with it and a simulation study evaluating their performance. Ecography. 2013:36:27-46.

38. Nafiu $\mathrm{OO}$, Onyewuche V. Association of abdominal obesity in children with perioperative respiratory adverse events. J Perianesth Nurs. 2014;29:84-93.

39. Hosmer DW, Hosmer T, Cessie SL, Lemeshow S. A comparison of goodnessof-fit tests for the logistic regression model. Stat Med. 1997;16:965-80.

40. Brightman HS, Milton DK, Wypij D, Burge HA, Spengler JD. Evaluating building-related symptoms using the US EPA BASE study results. Indoor Air. 2008;18:335-45.

41. Reinikainen LM, Jaakkola JJK, Seppaenen O. The effect of air humidification on symptoms and perception of indoor air quality in office workers: a sixperiod cross-over trial. Arch Environ Health. 1992;47:8-15.

42. Reinikainen LM, Jaakkola JJK. Significance of humidity and temperature on skin and upper airway symptoms. Indoor Air. 2003;13:344-52.

43. Sunwoo Y, Chou C, Takeshita J, Murakami M, Tochihara Y. Physiological and subjective responses to low relative humidity. J Physiol Anthropol. 2006;25:7-14

44. Sunwoo Y, Chou C, Takeshita J, Murakami M, Tochihara Y. Physiological and subjective responses to low relative humidity in young and elderly men. J Physiol Anthropol. 2006:25:229-38.

45. Ministry of the Environment. Annual Report on the Environment in Japan 2006. Tokyo: Environmental Strategy Division, Environmental Policy Bureau, Ministry of the Environment; 2006.

46. Fanger PO. Thermal comfort. Analysis and applications in environmental engineering. New York: McGraw-Hill; 1970

47. Ishii A, Iwamoto S, Yamashita M, Katayama T, Shiotsuki Y. An experimental study on the effect of humidity on thermal sensations of people in summer. J Therm Biol. 1994;18:387-91.

48. Lu CY, Lin JM, Chen YY, Chen YC. Building-related symptoms among office employees associated with indoor carbon dioxide and total volatile organic compounds. Int J Environ Res Public Health. 2015:12:5833-45.

49. Glas B, Stenberg B, Stenlund H, Sunesson AL. Exposure to formaldehyde, nitrogen dioxide, ozone, and terpenes among office workers and associations with reported symptoms. Int Arch Occup Environ Health. 2015; 88:613-22.

50. Rios $J$, Boechat $J$, Gioda A, dos Santos CY, de Aquino Neto FR, Lapa e Silva JR. Symptoms prevalence among office workers of a sealed versus a non-sealed building: associations to indoor air quality. Environ Int. 2009;35:1136-41.

51. Ooi PL, Goh KT, Phoon MH, Foo SC, Yap HM. Epidemiology of sick building syndrome and its associated risk factors in Singapore. Occup Environ Med. 1998:55:188-93.

52. Kipen HM, Fiedler N. Environmental factors in medically unexplained symptoms and related syndromes: The evidence and the challenge. Environ Health Perspect. 2002;110 suppl 4:597-9. 